\title{
Databasing Molecular Identities of Sugarcane (Saccharum spp.) Clones Constructed with Microsatellite (SSR) DNA Markers
}

\author{
Yong-Bao Pan \\ Sugarcane Research Laboratory, Houma, USA. \\ Email: yongbao.pan@ars.usda.gov \\ Received October $1^{\text {st }}, 2010$; revised October $31^{\text {st }}, 2010$; accepted November $13^{\text {th }}, 2010$.
}

\begin{abstract}
This paper reports the development of the first SSR marker-based sugarcane (Saccharum spp.) molecular identity database in the world. Since 2005, 1,025 sugarcane clones were genotyped, including 811 Louisiana, 45 Florida, 39 Texas, 130 foreign, and eight consultant/seed company clones. Genotyping was done on a fluorescence-capillary electrophoresis detection platform involving 21 highly polymorphic SSR markers that could potentially amplify 144 distinctive DNA fragments. Genotyping data were processed with the GeneMapper ${ }^{\mathrm{TM}}$ software to reveal electrophoregrams that were manually checked against the 144 fragments. The presence $(A)$ or absence $(C)$ of these 144 fragments in any sugarcane clone was recorded in an affixed sequence order as a DNAMAN ${ }^{\circledR}$ file to represent its molecular identity being achieved into a local molecular identity database. The molecular identity database has been updated annually by continued genotyping of newly assigned sugarcane clones. The database provides molecular descriptions for new cultivar registration articles, enables sugarcane breeders to identify mis-labeled sugarcane clones in crossing programs and determine the paternity of cross progeny, and ensures the desired cultivars are grown in farmers' fields.
\end{abstract}

Keywords: Sugarcane (Saccharum spp.), Breeding, SSR Marker, Molecular Identity Database

\section{Introduction}

Sugarcane (Saccharum spp.) is a complex aneu-polyploidy plant $(2 n=8 x$ or $10 x=100-130)$ that propagates asexually through planting of vegetative cuttings (setts) of mature stalks [1,2]. A sugarcane breeding cycle in Louisiana takes 12 years. This cycle begins with cross hybri dization and continues with field evaluation and selection, advancement, and multi-year, multi-location testing, and ending with the release of a new cultivar [3]. During this cycle, exchange and shipment of elite clones and breeding lines in the form of stalk cuttings (setts) across different test locations occur regularly for the purposes of verifying parental source or desired use of a clone in an experiment. Traditional tools for sugarcane breeders to identify different varieties rely on anatomical and morphological characters [1,4]. In Louisiana, the morphological descriptors, stalk wax, leaf sheath wax, leaf sheath margin, leaf sheath hair (pubescence), dewlap appearance, stalk color, auricle size and color, and other distinguishing characteristics, are used by Louisiana sugarcane breeders [5]. Others may use sugarcane descrip- tors available under the USDA-ARS GRIN system (http://www.ars-grin.gov/npgs/descriptors/sugarcane). Although these morphological descriptors may serve breeders who are directly involved in the evaluation and selection of those clones, breeders from other locations or researchers in other disciplines may not be familiar with these morphological traits, especially traits for which differential expression is already known to be strongly influenced by the environment. Therefore, it is not uncommon that mislabeling or misidentification of sugarcane clones occurs from time to time, whether on crossing carts or in the field plots (Jim Miller, personal communication, 2003). It might be worth noting that cumulative probability of this error may be high for parental clones that are propagated many times over the years (Phil Jackson, personal communication, 2010). Because of this, sugarcane pedigree information sometimes may not be so reliable (Karl J. Nuss, personal communication, 2003). Thus, to ensure correct variety identity and its genetic pedigree, a procedure for accurate identification using molecular data is urgently needed [6-8]. 
Microsatellite or simple sequence repeats (SSRs) DNA markers are short DNA fragments that contain various numbers of tandem repeat units of di-, tri-, tetra- or composite-nucleotide motifs $[9,10]$. SSR markers are useful for genotyping sugarcane because they are abundant, co-dominantly inherited, and highly reproducible $[11,12]$. Since the beginning of the century, a highthroughput molecular genotyping technology has been developed for sugarcane $(6,8)$. By using a fluorescence/capillary electrophoresis (CE)-based genotyping system, a total of 144 distinctive SSR DNA fragments were consistently amplified among the U.S. sugarcane germplasm from primer pairs of 21 polymorphic SSR DNA markers [13]. The 144 DNA fragments were arranged in a linear order in an Excel spreadsheet, which was used to score the presence (denoted by A) or absence (C) of each fingerprint from a sugarcane clone. The unique sequence of As or Cs was then converted to a DNAMAN $^{\circledR}$ (Lynnon Biosoft, Vaudreuil, Canada) file to represent the molecular identity of that clone.

This paper describes the development of the first sugarcane molecular identity database that has been used by the sugarcane breeders as a molecular breeding tool.
Unlike the anatomical and morphological traits that are influenced by environment, SSR DNA marker-based molecular identities represent stable genetic fingerprints that are not affected by geographical region or seasonal changes. With the advent of this molecular breeding tool [6], U.S. sugarcane breeders have been able to provide a molecular descriptor for new variety releases, identify any sugarcane clone that has been mislabeled [7-8], identify $S$. spontaneum cytoplasm-derived hybrids for trait introgression without violating the noxious weed regulations, and determine paternity of clones derived from polycrosses [14].

\section{Materials and Methods}

\subsection{SSR Markers and Genotyping Sample Collection}

Primer pairs of 21 highly polymorphic SSR markers developed by the International Consortium of Sugarcane Biotechnologists [11] based on the genomic DNA sequence of sugarcane cultivars Q124 and R570 were used. The nucleotide sequences and annealing temperatures of these primer pairs are listed in Table 1. The 5' ends of

Table 1. Sugarcane SSR markers, annealing temperatures, and primer sequences.

\begin{tabular}{|c|c|c|c|}
\hline SSR Name* & Anneal $\left({ }^{\circ} \mathrm{C}\right)$ & Forward Primer ( $5^{\prime}$ to $\left.3^{\prime}\right)$ & Reverse Primer ( $5^{\prime}$ to $\left.3^{\prime}\right)$ \\
\hline SMC119CG & 58 & TTC ATC TCT AGC CTA CCC CAA & AGC AGC CAT TTA CCC AGG A \\
\hline SMC1604SA & 58 & AGG GAA AAG GTA GCC TTG G & TTC CAA CAG ACT TGG GTG G \\
\hline SMC18SA & 62 & ATT CGG CTC GAC CTC GGG AT & AGT CGA AAG GTA GCG TGG TGT TAC \\
\hline SMC24DUQ & 64 & CGC AAC GAC ATA TAC ACT TCG G & CGA CAT CAC GGA GCA ATC AGT \\
\hline SMC278CS & 64 & TTC TAG TGC CAA TCC ATC TCA GA & CAT GCC AAC TTC CAA ACA GAC T \\
\hline SMC31CUQ & 62 & CAT GCC AAC TTC CAA TAC AGA CT & AGT GCC AAT CCA TCT CAG AGA \\
\hline SMC334BS & 60 & CAA TTC TGA CCG TGC AAA GAT & CGA TGA GCT TGA TTG CGA ATG \\
\hline SMC336BS & 62 & ATT CTA GTG CCA ATC CAT CTC A & CAT GCC AAC TTC CAA ACA GAC \\
\hline SMC36BUQ & 64 & GGG TTT CAT CTC TAG CCT ACC & TCA GTA GCA GAG TCA GAC GCT T \\
\hline SMC486CG & 58 & GAA ATT GCC TCC CAG GAT TA & CCA ACT TGA GAA TTG AGA TTC G \\
\hline SMC569CS & 62 & GCG ATG GTT CCT ATG CAA CTT & TTC GTG GCT GAG ATT CAC ACT A \\
\hline SMC7CUQ & 60 & GCC AAA GCA AGG GTC ACT AGA & AGC TCT ATC AGT TGA AAC CGA \\
\hline SMC597CS & 64 & GCA CAC CAC TCG AAT AAC GGA T & AGT ATA TCG TCC CTG GCA TTC A \\
\hline SMC703BS & 62 & GCC TTT CTC CAA ACC AAT TAG T & GTT GTT TAT GGA ATG GTG AGG A \\
\hline SMC851MS & 58 & ACT AAA ATG GCA AGG GTG GT & CGT GAG CCC ACA TAT CAT GC \\
\hline mSSCIR66 & 48 & AGG TGA TTT AGC AGC ATA & CAC AAA TAA ACC CAA TGA \\
\hline mSSCIR3 & 60 & ATA GCT CCC ACA CCA AAT GC & GGA CTA CTC CAC AAT GAT GC \\
\hline SMC1751CL & 60 & GCC ATG CCC ATG CTA AAG AT & ACG TTG GTC CCG GAA CCG \\
\hline SMC22DUQ & 62 & CCA TTC GAC GAA AGC GTC CT & CAA GCG TTG TGC TGC CGA GT \\
\hline mSSCIR43 & 52 & ATT CAA CGA TTT TCA CGA G & AAC CTA GCA ATT TAC AAG AG \\
\hline $\operatorname{mSSCIR74}$ & 54 & GCG CAA GCC ACA CTG AGA & ACG CAA CGC AAA ACA ACG \\
\hline
\end{tabular}


the forward primers were labeled with one of three fluorescent phosphoramidite dyes, FAM, VIC, or NED (Applied Biosystems, Foster City, CA). For U.S. cultivars and advanced breeding clones, leaf samples were collected from healthy younger leaves without disease symptoms from sugarcane plants maintained on the crossing carts, breeding nurseries, varietal trials, quarantine facilities, or commercial fields. For foreign sugarcane cultivars, either leaf samples collected from clones grown at USDA-ARS, SRL or genomic DNA samples obtained from foreign sugarcane breeding programs were used.

\subsection{Leaf DNA Extraction}

Leaf DNA was extracted by either using CTAB-beta mercaptoethanol [15] or hot $\mathrm{NaOH}-$ Tween 20 buffer [16]. For the CTAB-beta mercaptoethanol buffer procedure, total nucleic acids were extracted from approximately $200 \mathrm{mg}$ fresh leaf tissue by blending in a 2-ml microfuge tube containing $1 \mathrm{ml} \mathrm{CTAB}$ extraction buffer $[2 \% \mathrm{CTAB}$, $1.4 \mathrm{M} \mathrm{NaCl}, 20 \mathrm{mM}$ EDTA, $100 \mathrm{mM}$ Tris- $\mathrm{HCl}$ (pH 8.0), $2 \mu \mathrm{l}$ beta-mercaptoethanol added prior to extraction] and a $4.5 \mathrm{~mm}$ diameter sterile chrome-steel bead by violently shaking the tube using a Mini-Bead-BeaterTM (BioSpec Products, Inc., Bartleville, OK) for 1 min. The leaf homogenate was incubated at $60^{\circ} \mathrm{C}$ for $30 \mathrm{~min}$, extracted once with $0.75 \mathrm{ml}$ chloroform/isoamyl alcohol (24/1) by centrifuging at $6,000 \mathrm{x} \mathrm{g}$ for $10 \mathrm{~min}$ at $4^{\circ} \mathrm{C}$ and transferring $600 \mu \mathrm{l}$ aqueous phase to a new microfuge tube that contained $500 \mu \mathrm{l}$ of cold isopropyl alcohol. The mixture was incubated at $-20^{\circ} \mathrm{C}$ for at least $1 \mathrm{hr}$ before centrifuging for $15 \mathrm{~min}$ at $12,000 \mathrm{x} \mathrm{g}$. The resulting pellet was washed with $500 \mu \mathrm{l}$ of $70 \%$ ethanol plus $10 \mathrm{mM}$ sodium acetate and centrifuged for $10 \mathrm{~min}$ at $12,000 \mathrm{x}$ g to collect the nucleic acid pellet. Excess wash solution was evaporated in a DNA 120 SpeedVac System (Savant Instruments, Inc., Holbrook, NY) and the pellet was rehydrated in $200 \mu \mathrm{l}$ sterile water. The DNA concentration was determined using NanoDrop1000 (Thermo Scientific, Wilmington, DE) and adjusted to $10 \mu \mathrm{g} / \mu \mathrm{l}$ accordingly. For the hot $\mathrm{NaOH}-\mathrm{Tw}$ ween 20 buffer procedure, small pieces (about $30 \mathrm{~mm} 2$ ) of leaf tissue were excised from the youngest fully expanded leaves and dislodged into sample wells of a 96-well microplate that was pre-loaded with $50 \mu \mathrm{l}$ of a freshly prepared denaturing buffer (100 $\mathrm{mM} \mathrm{NaOH}$ and $2 \%$ Tween-20). The plates were sealed with aluminum sealing tape, incubated at $95^{\circ} \mathrm{C}$ for 10 $\mathrm{min}$, placed on ice for three min, and spun at $1,480 \mathrm{x} \mathrm{g}$ for $1 \mathrm{~min}$. Fifty $\mu \mathrm{l}$ of a neutralization buffer $(100 \mathrm{mM}$ Tris- $\mathrm{HCl}$ and $2 \mathrm{mM}$ EDTA) were then added to each well. The plates were re-sealed with aluminum sealing tape; the buffers were mixed by vortex, and spun at 1,480 $\mathrm{x} g$ for $1 \mathrm{~min}$. The resulting supernatants were transferred to a fresh sterile 96-well microplate.

\subsection{Semi-Automatic PCR and CE}

Fifty- $\mu$ l aliquots that were either diluted DNA samples from the $\mathrm{CTAB}$ procedure or supernatant from the $\mathrm{NaOH}-\mathrm{Tw} w e e n 20$ procedure were transferred into the wells of 96-well microplates. Plates were sent to the USDA-ARS, Mid-South Area Genomics Laboratory in Stoneville, MS for high throughput PCR and CE-based fragment analyses. A robot machine, the Hamilton's Microlab Star Liquid Handling Station (Hamilton Company, Reno, NV), was used to consolidate the DNA samples from four 96-well plates into a single 384-well plate and prepare 384-well PCR amplification reaction plates containing a 5- $\mu$ l PCR reaction mixture within each well. The PCR reaction mixture consisted of $0.25 \mu \mathrm{l}$ of the DNA sample, $0.5 \mu \mathrm{l}$ of $10 \mathrm{X}$ Buffer, $0.3 \mu \mathrm{l}$ of $25 \mathrm{mM}$ $\mathrm{MgCl}_{2}, 0.1 \mu \mathrm{l}$ of $10 \mathrm{mM}$ dNTPs, $0.41 \mu \mathrm{l}$ each of $3 \mathrm{pm} / \mu \mathrm{l}$ forward and reverse primers, $0.5 \mu \mathrm{l}$ of $10 \mathrm{mg} / \mathrm{ml} \mathrm{BSA}-\mathrm{V}$, $0.5 \mu \mathrm{l}$ of $100 \mu \mathrm{g} / \mu \mathrm{l} \mathrm{PVP}-40,0.025 \mu \mathrm{l}$ of 5 Units $/ \mu \mathrm{l} \mathrm{Taq}$, and $2.0 \mu \mathrm{l}$ of PCR water. PCR amplification reactions were conducted on a DNA Engine Tetra equipped with four 384-well Alpha blocks with heated lids (Bio-Rad Laboratories, Hercules, CA) under a program of $95^{\circ} \mathrm{C}$ for $15 \mathrm{~min}, 40$ cycles of $94^{\circ} \mathrm{C}$ for $15 \mathrm{sec}$, annealing for 15 sec, and $72^{\circ} \mathrm{C}$ for $1 \mathrm{~min}$, final extension at $72^{\circ} \mathrm{C}$ for 10 min, and holding at $4^{\circ} \mathrm{C}$. When PCR amplification was complete, the robot was used again to prepare 384-well CE sample plates by first diluting the amplified SSR DNA fragments and then mixing in each well one $\mu$ l of the diluted products with nine $\mu \mathrm{lHi}$-Dye formamide solution premixed with the GeneScan ${ }^{\mathrm{TM}} \operatorname{Rox}^{\mathrm{TM}} 500$ Size Standard. The CE sample plates were subjected to automated fragment analysis by ABI3730XL following manufacturer's instruction to produce Genescan files (Applied Biosystems, Inc., Foster City, CA).

\subsection{GeneMapper ${ }^{\circledR}$ Analysis, Construction of Molecular Identity (ID), and Clone Identity Check}

Genescan files were downloaded online from the file download site of the MSA Genomics Laboratory home page (https://msa.ars.usda.gov/computerhelp/upload/) and archived into individual folders named after sugarcane clones before being processed with the GeneMapper ${ }^{\mathrm{TM}}$ software (Applied Biosystems, Inc., Foster City, CA). The software calibrated SSR fragments based on the GeneScan $^{\mathrm{TM}} \mathrm{Rox}^{\mathrm{TM}} 500$ Size Standard and revealed SSR fragments in the Sample Plot Window, which were interpreted and scored manually. True SSR fragments that could be scored exhibited measurable fluorescence peaks. When both "plus-adenine" and "Minus-adenine" DNA 
fragments were present, only "plus-adenine" DNA fragments were scored. Fragments that showed measurable, yet inconsistent, fluorescence peaks such as "stutters", "pull-ups", or "dinosaur tails" [6] were not scored either. For the genotyping project, only 144 distinctive SSR DNA fragments [8] were targeted during the manual scoring process (Figure 1). Presence of any SSR fragment was given a score of "A"; while the absence of any SSR fragment was given a score of "C". The resulting linear sequence of "A" or " $\mathrm{C}$ " was converted to a DNAMAN $^{\circledR}$ sequence file to represent the molecular identity of that particular clone. The DNAMAN ${ }^{\circledR}$ file was named according to a general formula "Clone Name_Location_Year" before being stored in a local molecular identity database.

Whenever there is need for clone identity, the identity of the clone in question is aligned with all other identities available from the database using DNAMAN ${ }^{\circledR}$ software (Lynnon Biosoft, Vaudreuil, Canada). The algorithm first produces a homology matrix based on the sequence variability among molecular identities and then applies a correction method [17] before aligning all sequences progressively. Dynamic Alignment Method is used with analytical parameters set at "10" for gap open penalty, " 5 " for gap extension penalty, and " $40 \%$ " for delay divergent sequences. Bootstrap values were obtained upon 1,000 trials.

\begin{tabular}{|c|c|c|c|c|c|c|c|c|c|c|c|c|c|c|c|c|c|c|c|c|c|c|}
\hline \multirow{4}{*}{ I } & \multicolumn{5}{|c|}{ SMC119CG } & \multicolumn{6}{|c|}{ SMC1604SA } & \multicolumn{5}{|c|}{ SMC18SA } & \multicolumn{6}{|c|}{ SMC24DUQ } \\
\hline & 106 & 112 & 118 & 128 & 131 & 109 & 112 & 115 & 118 & 121 & 124 & 137 & 140 & 144 & 147 & 150 & 126 & 128 & 131 & 135 & 137 & 142 \\
\hline & 1 & 2 & 3 & 4 & 5 & 6 & 7 & 8 & 9 & 10 & 11 & 12 & 13 & 14 & 15 & 16 & 17 & 18 & 19 & 20 & \begin{tabular}{|l|}
21 \\
\end{tabular} & 22 \\
\hline & \multicolumn{5}{|c|}{5} & \multicolumn{6}{|c|}{6} & \multicolumn{5}{|c|}{5} & \multicolumn{6}{|c|}{6} \\
\hline \multirow{4}{*}{ II } & \multicolumn{9}{|c|}{ SMC278CS } & \multicolumn{11}{|c|}{ SMC31CUQ } & & \\
\hline & 140 & 153 & 166 & 168 & 170 & 174 & 176 & 178 & 182 & 138 & 150 & 160 & 162 & 163 & 165 & 167 & 171 & 173 & 177 & 179 & & \\
\hline & 23 & 24 & 25 & 26 & 27 & 28 & 29 & 30 & 31 & 32 & 33 & 34 & 35 & 36 & 37 & 38 & 39 & 40 & 41 & 42 & & \\
\hline & \multicolumn{9}{|c|}{9} & \multicolumn{11}{|c|}{11} & & \\
\hline \multirow{4}{*}{ III } & \multicolumn{6}{|c|}{ SMC334BS } & \multicolumn{11}{|c|}{ SMC336BS } & \multicolumn{3}{|c|}{ SMC36BUQ } & & \\
\hline & 146 & 149 & 151 & 161 & 163 & 164 & 141 & 154 & 164 & 166 & 167 & 169 & 171 & 173 & 175 & 177 & 183 & 112 & 118 & 121 & & \\
\hline & 43 & 44 & 45 & 46 & 47 & 48 & 49 & 50 & 51 & 52 & 53 & 54 & 55 & 56 & 57 & 58 & 59 & 60 & 61 & 62 & & \\
\hline & & & 6 & & & & & & & & & 11 & & & & & & & 3 & & & \\
\hline \multirow{4}{*}{ IV } & \multicolumn{5}{|c|}{ SMC486CG } & \multicolumn{5}{|c|}{ SMC569CS } & \multicolumn{6}{|c|}{ SMC7CUQ } & & & & & & \\
\hline & 224 & 227 & 237 & 239 & 241 & 167 & 170 & 210 & 219 & 222 & 158 & 162 & 164 & 166 & 168 & 170 & & & & & & \\
\hline & 63 & 64 & 65 & 66 & 67 & 68 & 69 & 70 & 71 & 72 & 73 & 74 & 75 & 76 & 77 & 78 & & & & & & \\
\hline & & & 5 & & & & & 5 & & & & & 6 & & & & & & & & & \\
\hline & & & & & SM & C597 & & & & & & & & & SM & $\mathrm{C703}$ & & & & & & \\
\hline $\mathrm{V}$ & 144 & 148 & 154 & 157 & 159 & 161 & 163 & 164 & 165 & \begin{tabular}{|l|}
168 \\
\end{tabular} & 174 & 201 & 206 & \begin{tabular}{|l|}
208 \\
\end{tabular} & 210 & 212 & 214 & 216 & 220 & 222 & & \\
\hline & 79 & 80 & 81 & 82 & 83 & 84 & 85 & 86 & 87 & 88 & 89 & 90 & 91 & 92 & 93 & 94 & 95 & 96 & 97 & 98 & & \\
\hline & & & & & & 11 & & & & & & & & & & 9 & & & & & & \\
\hline & & & MC8 & 51MS & & & & mSSC & IR66 & & & & & & $\mathrm{mSSC}$ & IR3 & & & & & & \\
\hline VI & 128 & 130 & 132 & 134 & 136 & 141 & 127 & 130 & 132 & 134 & 141 & 145 & 171 & \begin{tabular}{|l|}
173 \\
\end{tabular} & 175 & 177 & 178 & 180 & 182 & 187 & & \\
\hline & 99 & 100 & 101 & 102 & 103 & 104 & 105 & 106 & 107 & 108 & 109 & 110 & 111 & \begin{tabular}{|l|l|}
112 \\
\end{tabular} & 113 & 114 & 115 & 116 & 117 & 118 & & \\
\hline & & & 6 & & & & & 4 & 4 & & & & & & 1 & & & & & & & \\
\hline & & SM & $\mathrm{C} 1751$ & CL & & & & SM & C22D & UQ & & & & & & $\mathbf{m S}$ & SCIR & & & & & \\
\hline VI & 140 & 144 & 147 & 151 & 154 & 125 & 148 & 151 & 154 & 157 & 160 & 163 & 206 & 209 & 233 & 235 & 237 & 239 & 248 & 250 & 252 & \\
\hline & 119 & 120 & 121 & 122 & 123 & 124 & 125 & 126 & 127 & 128 & 129 & 130 & 131 & \begin{tabular}{|l|}
132 \\
\end{tabular} & 133 & 134 & 135 & 136 & 137 & 138 & 139 & \\
\hline & & & 5 & & & & & & 7 & & & & & & & & 9 & & & & & \\
\hline & & & SCIR & & & & & & & & & & & & & & & & & & & \\
\hline VI & 217 & 220 & 223 & 226 & 229 & & & & & & & & & & & & & & & & & \\
\hline & 140 & 141 & 142 & 143 & 144 & & & & & & & & & & & & & & & & & \\
\hline & & & 5 & & & & & & & & & & & & & & & & & & & \\
\hline
\end{tabular}

Figure 1. A definition of sugarcane molecualr identity. Within each section (I, II, III, IV, V, VI, VII, and VIII), name of the SSR marker (first row), allele size (base pairs) (second row), sequential numerical order (third row), and number of allele per marker (fourth row) are shown. There are a total of 144 SSR alleles amplifiable from the primer pairs of 21 SSR markers. The molecular identity of any sugarcane clone is defined by a linear sequence of $A$ (presence) or $C$ (absence) of each of the 144 SSR alleles in the order shown. 


\section{Results}

\subsection{Number of Clones Genotyped}

From 2005 to 2008 , a total of 1,004 samples were genotyped targeting the 144 specific DNA fragments that were potentially amplifiable from the primer pairs of 21 SSR markers. These included 237 samples in 2005, 238 in 2006, 339 in 2007, and 190 in 2008. Most of the genotyping (803 samples or $78.3 \%$ ) was conducted on cultivars and newly assigned breeding lines from the Louisiana breeding programs. In addition, 45 (4.4\%) Florida, 39 (3.8\%) Texas, 130 (12.7\%) foreign, and eight $(0.8 \%)$ cultivar samples from consultants and seedcane companies were also genotyped (Table 2). Genotyping continues annually for the Louisiana sugarcane breeding program and on request for Florida, Texas, or foreign sugarcane breeding programs. Depending upon the needs for rigor identification, multiple samples are collected from the same clone grown at up to four different locations, in the same or different years.

\subsection{A SSR Molecular Identity Database}

A local SSR identity database was constructed in 2005 by creating a folder named as "Genotyping Database" inside the " $\mathrm{C}$ :/My documents/Breeding" folder located in the hard drive disk of a desktop PC operated by the Microsoft Windows program. The "C:/My documents/ Breeding/Genotyping Database" folder is expandable by creating additional sub-folders that are named after calendar year, for example, sub-folders $<2005>$, <2006>, $<2007>$, etc. (Figure 2). Within each sub-folder are molecular identity files or DNAMAN ${ }^{\circledR}$ files of sugarcane clones that are genotyped in that year. For example, the molecular identity of HoCP 00-950 [18], "CACACAACCCCCCAAAAAACCACCAACCC CCCCCAC-
ACCCCCACACACCCCACACCCCCCAA ACAAACCCCACCAACCCCCACAACCACCACAAA ACCCACAACCACCCCCCCACCCACAAAACAAAA ACCACACCAAAAAAAA", can be found in subfolders $<2005>$ as "HoCP00-950_H_05" or "HoCP00-950 Q_05", <2006> as "HoCP00-950_H_06" or "НoCP00950_Q_06", and <2008> as "НоCР00-950_CP_08", where $\bar{H}=$ Houma, $\mathrm{Q}=$ quarantine, $\mathrm{CP}=$ Canal Point.

\section{Discussion}

Conventional sugarcane breeding takes 12 years from initial cross hybridization to a new cultivar release [3]. This paper reports the development of the first SSR marker-based molecular identity database in sugarcane that can serve as an additional tool to ensure that breeders have the correct clones involved in their crosses as well as varietal trials. Unlike the anatomical and morphological traits, SSR DNA marker-based molecular identities represent stable genetic fingerprints that are not affected by location or seasonal changes [7-8]. Since its initial establishment in 2005 , the database has been

Table 2. Number of sugarcane clones genotyped with SSR markers (2005-2008).

\begin{tabular}{lccccc}
\hline \multicolumn{1}{c}{ Sample Collection Site } & 2005 & 2006 & 2007 & 2008 & TOTAL \\
\hline USDA at Houma, FL & 57 & 41 & 126 & 131 & 355 \\
USDA at Canal Point, FL & 78 & 97 & 91 & 49 & 315 \\
LSU & 52 & 46 & 28 & 7 & 133 \\
Florida & 3 & 34 & 6 & 2 & 45 \\
Texas & 32 & 7 & 0 & 0 & 39 \\
Consultants/Companies & 2 & 0 & 3 & 3 & 8 \\
Foreign & 13 & 20 & 85 & 12 & 130 \\
TOTAL & 237 & 245 & 339 & 204 & 1,025 \\
\hline
\end{tabular}

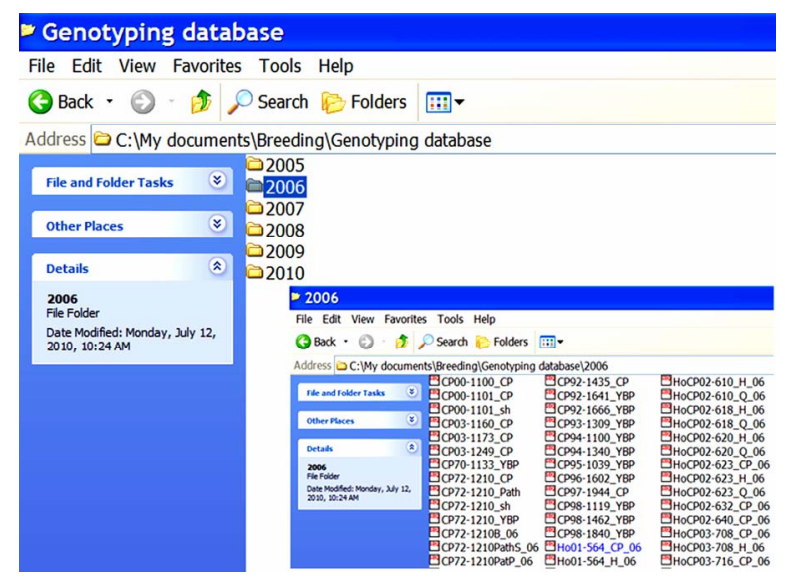

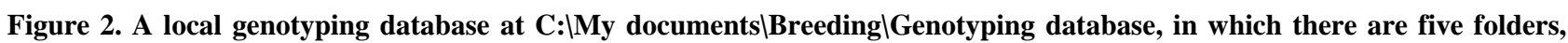
namely, 2005, 2006, 2007, 2008, and New Folder. Part of the Folder 2006 is shown listing molecular identity files of a few sugacrane clones that were genotyped in 2006. 
updated each year with newly acquired molecular identities. It has also been demonstrated that if a Louisiana sugarcane clone was correctly labeled, then the same molecular identity would be produced using the same fluorescence- and CE-based SSR genotyping protocol and the molecular identity would group together with those produced in prior years or different field plots from the same sugarcane clone. One recent example is shown in Figure 3 that deals with identity checks of three sugarcane clones, namely, ST-283, ST-299, and ST-950. After these clones were genotyped using the standard protocol, the resulting molecular identities were blindly aligned with those of all other Louisiana sugarcane clones constructed in 2005, 2006, and 2007 using the multiple sequence alignment program of DNAMAN ${ }^{\circledR}$ software (Lynnon Biosoft, Vaudreuil, Canada). The results verified that ST-283 was indeed cultivar L 01-283 (Panel A) and ST-299 was cultivar L 01-299 (Panel A). However, ST-950 was not cultivar HoCP 00-950 but clone Ho 01-564 (Panel B).

There are three other demonstrated applications of the reported molecular identity database. The primary and most important application of the molecular identity database is to protect sugarcane breeders' rights by provid- ing a molecular descriptor in their cultivar registration. These include Louisiana sugarcane cultivar Ho 95-988 [18], HoCP 96-540 [19], Ho 00-950 [20], HoCP 91-552 [21], and Ho 00-961 [22]. In addition, molecular descriptors were also included in sugarcane cultivar registration articles from the Florida sugarcane breeding program, including CPCL 97-2730 [23], CP 00-1101 [24], CP 88-1165 [25], CP 00-1446 [26], and CP 00-2180 [27]. All the molecular descriptors of newly released Louisiana sugarcane cultivars are produced from SSR DNA marker-based genotyping that are stored in the local molecular identity database.

The second application of the molecular identity database is to facilitate the exploration of S. spontaneum cytoplasm through conventional breeding and more general, to determine whether progeny are from proposed parents for any type of sugarcane cross, in particular, cross involving related wild species. Prior to the advent of SSR genotyping technology, there was no report on the use of the cytoplasmic genome of $S$. spontaneum clones in sugarcane breeding. Also, no genetic stock with $S$. spontaneum cytoplasm had ever been released. This is because $S$. spontaneum clones are designated as regulated noxious weeds with substantial self-pollination and vigorous

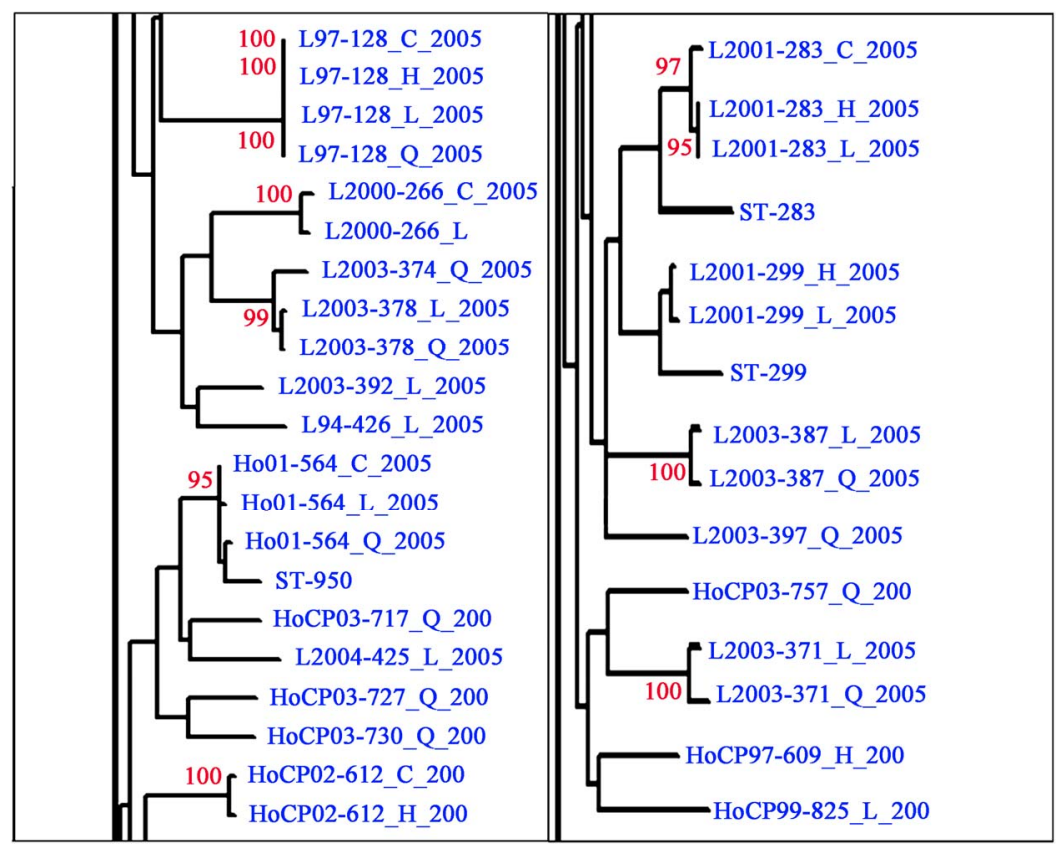

Figure 3. Molecular identity verification of three sugarcane clones, ST-283, ST-299, and ST-950 conducted in 2007. The molecular identities of ST-283, ST-299, and ST-950 were aligned with those of all Louisiana sugarcane clones that were

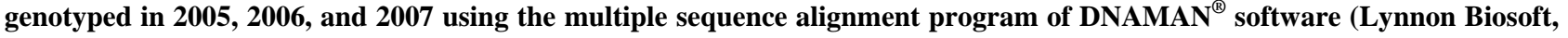
Vaudreuil, Canada). Results showed that ST-283 was cultivar L 2001-283 (Panel A), ST-299 was cultivar L 2001-299 (Panel A), and ST-950 was clone Ho 01-564 (Panel B). The dynamic alignment method is used with analytical parameters set at "10" for gap open penalty, “5” for gap extension penalty, and “ $40 \%$ ” for delay divergent sequences. The numerical values on the branches are bootstrapping (confidence) values based on 1,000 trials. 
rhizomes [28]. With the advent of SSR genotyping technology, sugarcane breeders have been able to use DNA marker information to identify true F1 progeny from selfs arising from crosses in which $S$. spontaneum clones were maternal parents before evaluation in the field ensuring the noxious weed regulations were not violated. A few $S$. spontaneum cytoplasm-derived clones have been reported, of which US 99-51 [29] and Ho 02-113 (unpublished data) produced consistently high yields of total dry mass.

A third but potential use of the molecular identity database is to determine the paternity of sugarcane progeny, particularly those from polycrosses [14]. When only a few tassels are available from desirable parents, sugarcane breeders must decide whether to make a limited number of bi-parental crosses or intersperse the tassels in a polycross to obtain a greater number of crosses and more seeds. Without the molecular identity information for the parental clones, breeders are not able to definitively determine the paternity information for polycross progeny. Using seven highly polymorphic SSR markers that produced parent-specific SSR alleles, Tew and Pan [14] were able to determine the paternity for 79 to $99 \%$ of the progeny from a seven-parent polycross, depending upon the maternal parent. The ability to identify paternity of polycross progeny with SSR DNA markers can be used in sugarcane breeding to maximize the number of desirable crosses from a limited source of flowers with minimal loss of pedigree information.

\section{Acknowledgements}

The high-throughput PCR and fragment analysis were conducted by Sheron Simpson at the USDA-ARS, MidSouth Area Genomics Laboratory, Stoneville, MS, directed by Brian E. Scheffler. Lionel Lomax and Jennifer Shaw provided technical assistance. The study was partially supported by the sugarcane grower/miller check-off funds administered by the American Sugar Cane League and the Florida Sugar Cane League.

Product names and trademarks are mentioned to report factually on available data; however, the USDA neither guarantees nor warrants the standard of the product, and the use of the name by USDA does not imply the approval of the product to the exclusion of others that may also be suitable.

\section{REFERENCES}

[1] D. J. Heinz, "Sugarcane Improvement through Breeding," Elsevier, Amsterdam.

[2] L. Grivet and P. Arruda, "Sugarcane Genomics: Depicting the Complex Genome of an Important Tropical Crop," Current Opinion in Plant Biology, Vol. 5, No. 2,
2002, pp. 122-127.

[3] K. P. Bischoff and K. A Gravois, "The Development of New Sugarcane Varieties at the LSU Ag Center," Journal of American Society Sugar Cane Technologists, Vol. 24, 2004, pp. 142-164.

[4] J. C. Skinner, "Description of Sugarcane Clones. III. Botanical Description," Proceedings International Society Sugar Cane Technologists, Vol. 14, 1972, pp. 124-127.

[5] C. LaBorde, B. Legendre, K. Bischoff, K. Gravois and T. Robert, "Sugarcane Variety Identification Guide 2008," Louisiana State University AgCenter Publication, Baton Rouge, 2008.

[6] Y.-B. Pan, G. M. Cordeiro, E. P. Richard Jr. and R. J. Henry, "Molecular Genotyping of Sugarcane Clones with Microsatellite DNA Markers," Maydica, Vol. 48, No. 4, 2003, pp. 319-329.

[7] Y.-B. Pan, J. D. Miller, R. J. Schnell, E. P. Richard Jr. and Q. Wei, "Application of Microsatellite and RAPD Fingerprints in the Florida Sugarcane Variety Program," Sugar Cane International, March-April 2003, pp. 19-28.

[8] Y.-B. Pan, B. S. Scheffler and E. P. Richard Jr., "High Throughput Genotyping of Commercial Sugarcane Clones with Microsatellite (SSR) DNA Markers," Sugar Tech, Vol. 9, No. 2, 2007, pp. 176-181.

[9] A. Edwards, A. Civitello, H. A. Hammond and C. T. Caskey, "DNA Typing and Genetic Mapping with Trimeric and Tetrameric Tandem Repeats," American Journal Human Genetics, Vol. 49, No. 4, 1991, pp. 746756.

[10] M. H. Polymeropoulos, H. Xiao, D. S. Rath and C. R. Merril, "Tetranucleotide Repeat Polymorphism at the Human Tyrosine Hydroxylase Gene," Nucleic Acids Research, Vol. 19, No. 13, 1991, p. 3753.

[11] G. M. Cordeiro, G. O. Taylor and R. J. Henry, "Characterisation of Microsatellite Markers from Sugarcane (Saccharum sp.), a Highly Polyploid Species," Plant Science, Vol. 155, No. 2, 2000, pp. 161-168.

[12] G. M. Cordeiro, R. Casu, C. L. McIntyre, J. M. Manners and R. J. Henry, "Microsatellite Markers from Sugarcane (Saccharum sp.) ESTs Transferable to Erianthus and Sorghum," Plant Science, Vol. 160, No. 6, 2001, pp. 1115-1123.

[13] Y.-B. Pan, "Highly Polymorphic Microsatellite DNA Markers for Sugarcane Germplasm Evaluation and Variety Identity Testing," Sugar Tech, Vol. 8, No. 4, 2006, pp. 246-256.

[14] T. L. Tew and Y.-B. Pan, "Microsatellite (Simple Sequence Repeat) Marker-Based Paternity Analysis of a Seven-Parent Sugarcane Polycross," Crop Science, Vol. 50, No. 4, 2010, pp. 1401-1408.

[15] Y.-B. Pan, D. M. Burner and B. L. Legendre, "An Assessment of the Phylogenetic Relationship among Sugarcane and Related Taxa Based on the Nucleotide Sequence of 5s Rrna Intergenic Spacers," Genetica, Vol. 108, No. 3, 2000, pp. 285-295. 
[16] Z. Xin, J. P. Velten, M. J. Oliver and J. J. Burke, "High-Throughput DNA Extraction Method Suitable for PCR,” BioTechniques, Vol. 34, No. 4, 2003, pp. 820-826.

[17] T. H. Jukes and C. R. Cantor, "Evolution of Protein Molecules," In: H. N. Munro, Ed., Mammalian Protein Metabolism, Academic Press, New York, 1969, pp. 21132.

[18] T. L. Tew, D. M. Burner, B. L. Legendre, W. H. White, M. P. Grisham, E. O. Dufrene Jr., D. D. Garrison, J. C. Veremis, Y.-B. Pan and E. P. Richard Jr., "Registration of 'Ho 95-988' Sugarcane," Crop Science, Vol. 45, No. 4, 2005, pp. 1660-1661.

[19] T. L. Tew, W. H. White, B. L. Legendre, M. P. Grisham, E. O. Dufrene Jr., D. D. Garrison, J. C. Veremis, Y.-B. Pan, E. P. Richard Jr. and J. D. Miller, "Registration of 'HoCP 96-540' Sugarcane,” Crop Science, Vol. 45, No. 2, 2005, pp. 785-786.

[20] T. L. Tew, W. H. White, M. P. Grisham, E. O. Dufrene, D. D. Garrison, Y.-B. Pan, E. P. Richard Jr., B. L. Legendre, and J. D. Miller, "Registration of 'HoCP 00-950' sugarcane," Journal Plant Registrations, Vol. 3, No. 1, 2009, pp. 42-50.

[21] T. L. Tew, E. O. Dufrene, W. H. White, R. M. Cobill, B. L. Legendre, M. P. Grisham, D. D. Garrison, Y.-B. Pan, E. P. Richard Jr., and J. D. Miller, "Registration of 'HoCP 91-552' High-Fiber Sugarcane,” Journal Plant Registrations, in press.

[22] W. H. White, R. M. Cobill, T. L. Tew, D. M. Burner, M. P. Grisham, E. O. Dufrene, Y.-B. Pan, E. P. Richard Jr. and B. L. Legendre, "Registration of 'Ho 00-961' Sugarcane," Journal Plant Registrations, in press.
[23] S. B. Milligan, R. W. Davidson, S. J. Edmé, J. C. Comstock, C. J. Hu, D. G. Holder, B. Glaz, N. C. Glynn and R. A. Gilbert, "Registration of 'CPCL 97-2730' Sugarcane," Journal Plant Registrations, Vol. 3, No. 2, 2009, pp. 158-164.

[24] R. A. Gilbert, J. C. Comstock, B. Glaz, S. J. Edmé, R. W. Davidson, N. C. Glynn, J. D. Miller and P. Y. P. Tai, "Registration of 'CP 00-1101' Sugarcane," Journal Plant Registrations, Vol. 2, No. 2, 2008, pp. 95-101.

[25] Juárez, J. L., J. D. Miller, H. Orozco, E. Solares, P. Y. P. Tai, J. C. Comstock, B. Glaz, J. L. Quemé de León, W. Ovalle, S. J. Edmé, N. C. Glynn, and C. W. Deren, "Registration of 'CP 88-1165' Sugarcane," Journal Plant Registrations, Vol. 2, No. 2, 2008, pp. 102-109.

[26] J. C. Comstock, B. Glaz, S. J. Edmé, R. W. Davidson, R. A. Gilbert, N. C. Glynn, J. D. Miller, and P. Y. P. Tai, "Registration of 'CP 00-1446' Sugarcane," Journal Plant Registrations, Vol. 3, No. 1, 2009, pp. 28-34.

[27] B. Glaz, S. J. Edmé, R. W. Davidson, R. A. Gilbert, J. C. Comstock, N. C. Glynn, J. D. Miller and P. Y.P. Tai, "Registration of 'CP 00-2180' Sugarcane," Journal Plant Registrations, Vol. 3, No. 1, 2009, pp. 35-41.

[28] P. Y. P. Tai, J. D. Miller and B. L. Legendre, "Preservation of Saccharum spontaneum Germplasm through Storage of True Seeds," Sugar Cane, Vol. 6, 1994, pp. 3-8.

[29] Y.-B. Pan, D. M. Burner, Q. Wei, G. M. Cordeiro, B. L. Legendre and R. J. Henry, "New Saccharum Hybrids in $S$. spontaneum Cytoplasm Developed through a Combination of Conventional and Molecular Breeding Approaches," Plant Genetic Resources, Vol. 2, No. 2, 2004, pp. 131-139. 